\title{
TRACING CYANOBACTERIAL BLOOMS TO ASSESS THE IMPACT OF WASTEWATERS DISCHARGES ON COASTAL AREAS AND LAKES
}

\author{
ROBERTA TETA, ${ }^{1}$ GERARDO DELLA SALA,${ }^{1}$ ALFONSO MANGONI, ${ }^{1}$ \\ MASSIMILIANO LEGA, ${ }^{2} \&$ VALERIA COSTANTINO ${ }^{1}$ \\ ${ }^{1}$ Department of Pharmacy, University of Naples Federico II. \\ ${ }^{2}$ Department of Engineering, University of Naples Parthenope.
}

\begin{abstract}
The rapid detection of cyanobacterial blooms has become an emerging and urgent need during the last years due to the increasing number of cyanobacterial harmful blooms (CHABs) all over the world. The main responsibility of this phenomenon is attributable to the nutrient enrichment, resulting from eutrophication processes of anthropogenic origin. The blooms deplete oxygen in surface waters through excessive bacterial respiration and decomposition and often release toxic substances (cyanotoxins) causing fish mortality and risks for public health. We have initiated a worldwide program for the early detection of cyanobacterial blooms using combined techniques based on chemical/biochemical analyses of samples collected on specific sites identified with remote/proximal sensing tools. Here we report our results obtained from the analysis of cyanobacterial blooms using a new powerful approach based on the combined use of LCMS/MS (Liquid Chromatography Tandem Mass Spectrometry) and Molecular Networking to detect the presence of known and novel cyanotoxins. In addition, we report the most recent results from our case studies on specific coastal areas and lakes, where the presence of cyanobacteria was confirmed to be related to the excess nutrient input of anthropogenic origin, resulting from wastewater discharges or runoff from fertilisers and manure spread on agricultural areas. The monitoring of bloom occurrence, composition, frequency and chemistry can provide important indicators of degraded water quality, supporting the Government Bodies in the evaluation of effectiveness of wastewater plans that insist on a specific coastal area.
\end{abstract}

Keywords: cyanobacterial bloom, molecular networking, NDVI index, remote sensing, toxin, wastewater.

\section{INTRODUCTION}

Cyanobacteria are a major group of bacteria that occur throughout the world, ubiquitous in aquatic and terrestrial environments. Freshwater, brackish or salt-water species can accumulate in surface water supplies as "blooms" and concentrate on the surface as blue-green "scums" [1].

They may become harmful if they occur in an unnaturally high abundance or if they produce a toxin. A high abundance of cyanobacteria can block sunlight to underwater grasses, consume oxygen in the water leading to fish kills, produce surface scum and odours, and interfere with the feeding of organisms that filter water to obtain their food [2].

Some species of cyanobacteria produce toxins, which are classified according to their mode of action into hepatotoxins (e.g. microcystins), neurotoxins (e.g. anatoxins), skin irritants, and other toxins. Therefore, they represent a serious risk for the public health, that is attracting the worldwide attention in the last years, due to the increase of the cyanobacterial 
harmuful algal blooms (CHAB). Not all cyanobacteria produce toxins but still there is little knowledge about what triggers toxin production by cyanobacteria. The two main factors that have been shown to affect toxin production are light and temperature. The optimum temperature for toxin production in cyanobacteria is between 20 and $25^{\circ} \mathrm{C}$ [3], which suggests that cyanobacteria are most toxic during periods with warm weather and in areas with warm climates. Light intensity is an important factor in toxin production in specific species, such as M. aeruginosa.

On the other side, they still represent an untapped source of novel lead compounds, such as smenamides and smenothiazoles $[4,5]$, for drug discovery. The monomethil auristatin-E, a semi-synthetic analogue of dolastatin-10 [6], is the first "cyanobacterial" drug approved by FDA as cytotoxic chemotherapeutic. Therefore, cyanobacteria inspire research activities throughout the world for both the risks and remedies they represent.

The cyanobacterial harmful bloom is caused by a combination of factors such as temperature, nutrients (Phosphorus, $\mathrm{P}$ and Nitrogen, N), sunlight (for the photosynthesis), and $\mathrm{pH}$ of the water. The warming climate and anthropogenically-enhanced nutrient loading in water systems have been cited as potential drivers of the intensity [7] and toxicity of CHABs [8]. The excessive inputs coming from domestic and industrial effluents, wastewaters, agriculture activities (pesticides and fertilizers), and inadequate management of watersheds cause an overproduction of vegetation (eutrophication), whose consequences are usually associated with low water quality, leading to a variety of problems ranging from anoxic waters to toxic algal blooms. Therefore cyanobacteria are symptoms of eutrophic conditions due to the anthropogenic pressure on waters, which receive diverse pollutants (wastewater or contaminated waters). For this reason and for their own toxicity, cyanobacteria inhabited waters can be considered as affected by environmental criticalities.

Cyanobacterial blooms are extremely patchy because the behaviour of different cyanobacterial taxa in nature is not homogeneous as their ecophysiological properties differ. Therefore, they often remain unobserved by current monitoring programs [9]. The increasing number of CHABs in the last years has urged the need of a method for the rapid detection of cyanobacteria in water bodies.

We have initiated a worldwide research program aimed to the development of a multidisciplinary strategy to the study of cyanobacteria and the CHABs.

In this paper, we report our analysis of Seattle Green Lake based on the combined use of in situ data and remote sensing tools $[10,11]$ for the detection of cyanobacteria and their toxins [12]. We chose the most popular Seattle Green Lake (Fig. 1) as a test bed of our approach because of the well-documented CHABs since the early 1900s, the low N:P ratio and the high Trophic State Index (TSI) [13].

The presence of toxic cyanobacteria in the Green Lake is confirmed by the results of the Washington State monitoring program [14]. On their data management system we queried about the status of the specific lake in the period comprised between August 2014 (our sampling campaign) to date. As synthesized in Fig. 2 at the selected site and time the presence of cyanobacteria and toxins exceeding the state recreational guidelines (more than $50 \%$ of the analysed samples) were detected.

\section{METHODS}

The coverage of the water surface by cyanobacterial bloom changes its colour, density, transparency and the reflection of energy. Abnormal phenomenon on colour, greyscale, form, texture and other characteristics are reflected on remote sensing image [15]. The spectral 


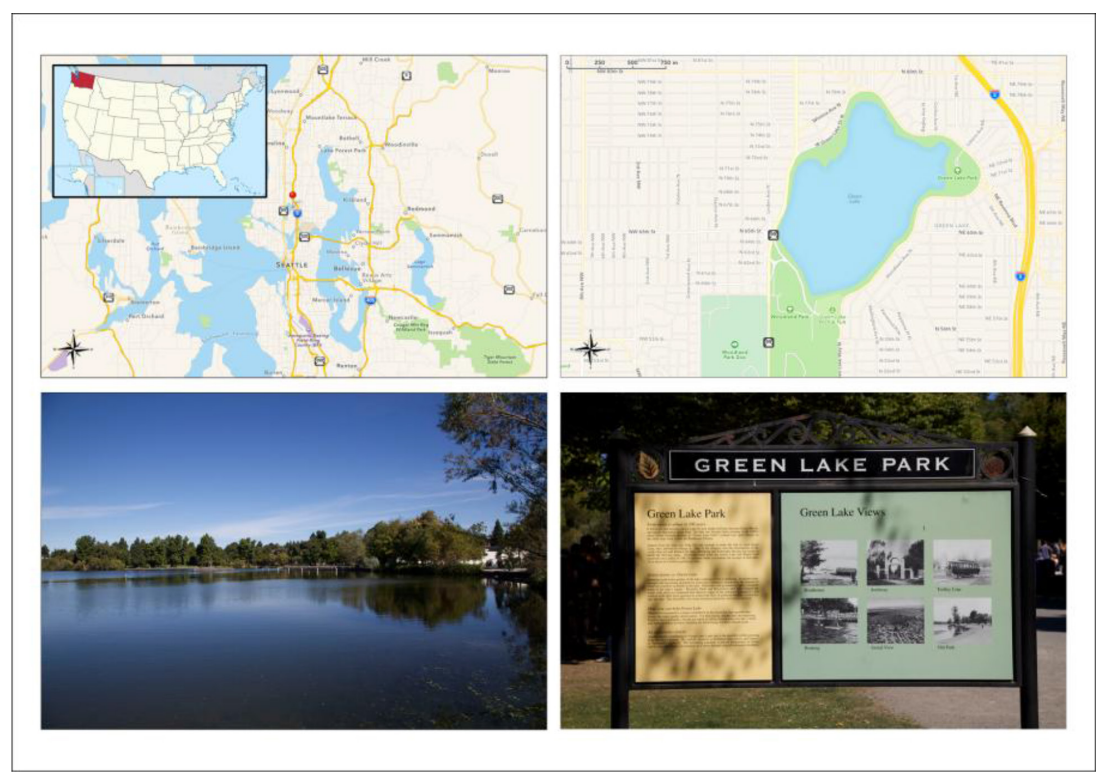

Figure 1: The popular Green Lake is a freshwater lake in north central Seattle, Washington, within Green Lake Park.

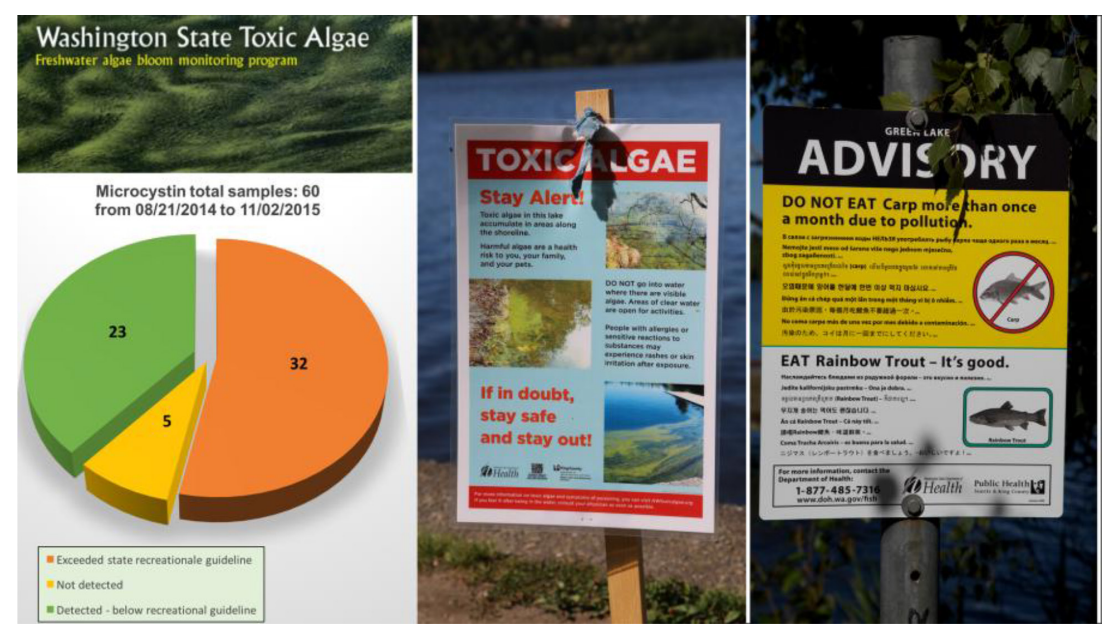

Figure 2: Results of the query to the Washington State Toxic Algae Monitoring Program (left) and warnings on the Green Lake shoreline at the time of sampling (right).

characteristics of cyanobacteria bloom and vegetation are similar, therefore NDVI (Normalized Difference Vegetation Index) is an effective index for extracting information related to cyanobacteria bloom. Multi-spectral data were obtained from the Landsat 8 from 16th September 2014; they were pre-processed with atmospheric correction routines, then used to compute NDVI, and finally pan-sharpened to $15 \mathrm{~m}$ for image analysis. The NDVI was 
computed as: NDVI $=(\mathrm{NIR}-\mathrm{R}) /(\mathrm{NIR}+\mathrm{R})$, where NIR is the near infrared band and $\mathrm{R}$ is the red band, and output will range from -1 to 1 . Five classes of NDVI were generated for the scene to illustrate different intensities of possible photosynthetic activity in the lake, and the classes 3, 4 and 5 with the higher probability to highlight the cyanobacterial bloom.

The sample collected at Green Lake Seattle during the cyanobacterial harmful algal bloom in the September 2014 was analysed with OPTECH, Biostar B3 microscope at $400 \mathrm{X}$ and $1,000 \mathrm{X}$ magnification as a first step for the qualitative detection of cyanobacteria and then treated as reported $[12,16]$. Cyanotoxins obtained from the freshwater cyanobacterial collection were studied using a new approach based on molecular networking analysis of LCMS/ MS data. Molecular networking [17] provides a visual representation of structural relationships as revealed by MS/MS data. A single chemical species is represented as a node and the relatedness between compounds is represented by an edge. Libraries containing a large number of MS/MS spectra of known natural products are available at the GNPS (Global Natural Product Social Molecular Network) website [18] for the purpose of dereplication. During the process of generation of the network, the spectra from one or more LC-MS/MS runs are compared pairwise, and each spectrum is also compared with spectra in the libraries. This strategy allows the identification not only of known metabolites, but also of their structural analogues (either new or known compounds which are not present in the library). The MSnetworking approach is particularly well suited for the detection of new cyanotoxin variants, and resulted in the discovery of a new microcystin, namely MC-MHtyR. To date, this new approach has not yet been used in the analysis of a cyanobacterial bloom. Metagenomic analysis $[19,20]$ of the sample allowed us to identify the bloom-forming cyanobacteria as a strain of Microcystis aeruginosa.

\section{RESULTS}

The combined use of in situ data and remote sensing on the study of the Green Lake cyanobacterial bloom allowed a fast and sensitive detection of cyanobacteria and their toxins in the collected sample. The NDVI classification identified an area of downwind accumulation of material along the shorelines, that corresponds to our sampling spot (ground truth 1, GT1). Buoyant cyanobacteria, pushed by light waves and wind, produced a scum accumulation on the shores that was clearly visible on the field (Fig. 3).

The confirmation of the presence of cyanobacteria in that place came from our in situ analysis. Microscopic observation of the sample showed the prevalence of round-shaped cyanobacteria that the metagenomic analysis indicated as Microcystis aeruginosa (Fig. 4).

Microcystis is a toxin-producing strain, it contains chiefly microcystin-LR, -RR and -YR, with some cultures showing all three variants, and some strains being dominated by one of them. Microcystin-LR is considered the most frequently occurring microcystin, and therefore searched and quantified in the current monitoring programs.

The presence of microcystins can limit the use of lakes and reservoirs for recreation activities, as drinking water reservoirs, and for irrigation and accounts for millions of dollars per year in the United States. The World Health Organisation (WHO) has set a provisional guideline value for MC-LR of $1.0 \mu \mathrm{g} / \mathrm{L}$ in drinking water and a level of 100,000 cyanobacterial cells/mL (equivalent to approximately $50 \mu \mathrm{g}$ chlorophyll-a/L if cyanobacteria dominate) as a guideline value for a moderate health alert in recreational waters [1]. In August/September 2014, Seattle Green Lake CHABs microcystin LR measurement of 23,800 $\mu \mathrm{g} / \mathrm{L}$ became the highest concentration ever recorded, not only for Green Lake, but for all of Washington State. The new microcystin we have discovered through the combined use of LCMS/MS and 


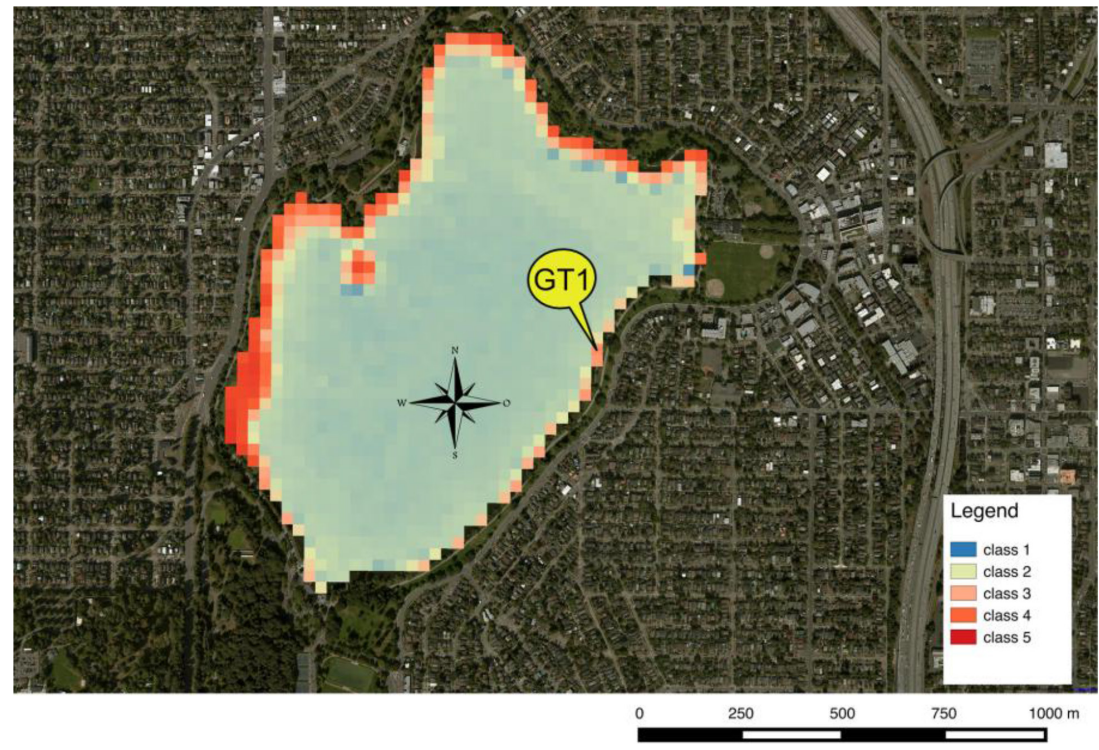

Figure 3: Landsat 8 NDVI classes to reveal cyanobacteria in Seattle Green Lake. GT1 is the sampling spot on September 16th, 2014.
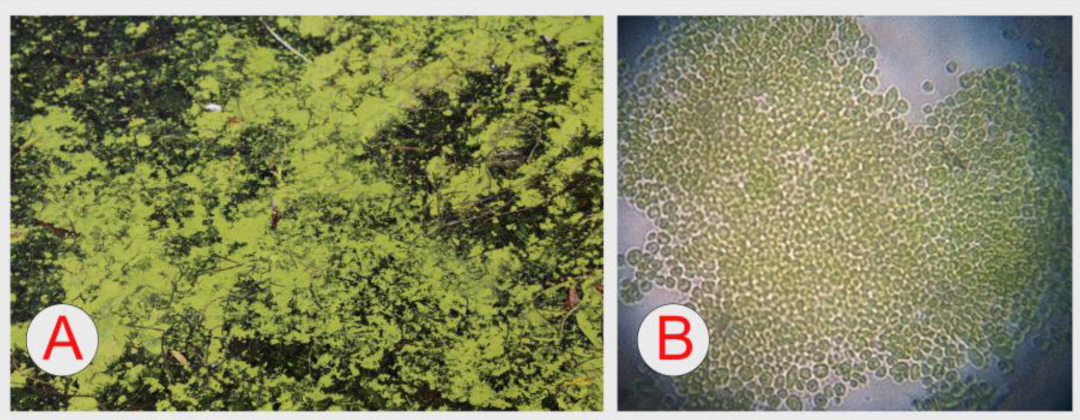

Figure 4: Buoyant cyanobacteria on the surface of the Green Lake waters at the sampling spot (A) and microscopic observation of the analysed sample (B).

molecular networking data (Figure 5), MC-MHtyR, comprises about half of the total MC content in the Green Lake bloom and this is not considered in the monitoring program. Most of the existing studies on the levels of microcystins in water supplies do not clearly indicate whether total or free microcystins were measured or which type of microcystin is more abundant. Molecular networking applied directly on a cyanobacterial blooms allows a complete survey of all the microcystins present in the sample, and a quantification of each type is also easily feasible [21]. 


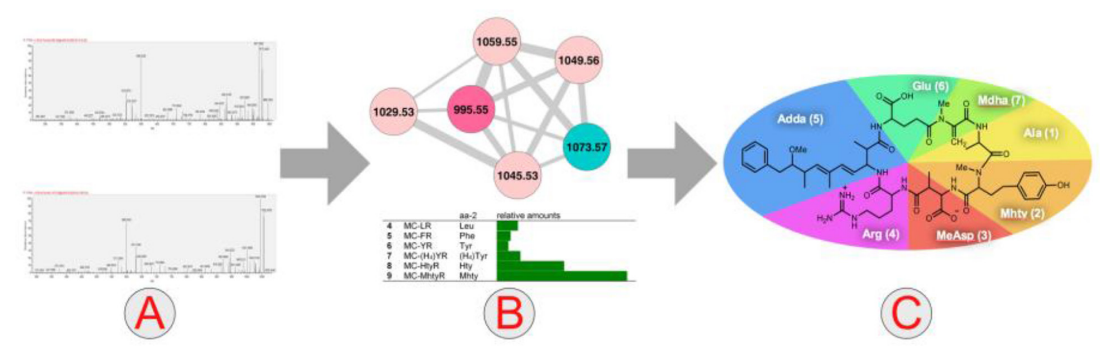

Figure 5: Overview of LCMS/MS and molecular networking strategy. (a) MS/MS spectra were acquired and submitted to GNPS website. (b) A molecular network was generated: each node is marked with the mass to charge ratio. A cluster contained microcystin LR (fuchsia node), five known microcystins (LR, FR, YR, $\left(\mathrm{H}_{4}\right) \mathrm{YR}$, HTyR, pink nodes) and the new congener (MC-MeHTyR, light blue node). (c) The structure of the new MC congener, that represents the half of the total MC content in the Seattle Green Lake extract.

\section{CONCLUSIONS}

The results of the analysis of the CHABs of Seattle Green Lake have confirmed the validity of the multidisciplinary approach to the detection of cyanobacterial blooms and toxins through the combined use of in situ data and remote sensing tools. Nowadays still some limitations remain to the use of remote sensing: the spatial resolution of the used satellite $(30 \mathrm{~m}$ for Landsat 8) is not suitable to detect the reduced size of the blooms when in an early stage of propagation and/or the water bodies with a reduced exposed surface (river, canal). Although the latest satellites expand the field of view, further reducing the resolution, a fee has to be corresponded. We aim to develop a hierarchical monitoring program involving aircrafts $[22,23]$ and drones $[24,25]$ for remote and proximal sensing [26], respectively. The newest tool of the molecular networking applied for the first time on a cyanobacterial bloom allowed a fast and sensitive detection of known and new toxin congeners in CHABs.

\section{ACKNOWLEDGEMENTS}

This work was funded by EC, FP7 2007-2013 under grant agreement nº 229893 (Bluegenics) and by Università di Napoli Federico II under the STAR project (SeaLEADS).

\section{REFERENCES}

[1] Guidelines for safe recreational water environments. Volume 1: Coastal and freshwaters, available at: http://www.who.int/water_sanitation_health/bathing/srwe1 execsum/ en/index6.html\#

[2] Water Quality of Green Lake - University of Washington, available at:https://courses. washington.edu/hypertxt/cgibin/students.washington.edu/zenhwang/greenlake/causes. html

[3] Department of Ecology - State of Washington, available at:http://www.ecy.wa.gov/ programs/wq/plants/algae/publichealth/GeneralCyanobacteria.html

[4] Teta, R., Irollo, E., Della Sala, G., Pirozzi, G., Mangoni, A. \& Costantino, V., Smenamides $\mathrm{A}$ and $\mathrm{B}$, chlorinated peptide/polyketide hybrids containing a dolapyrrolidinone unit from the Caribbean sponge Smenospongia aurea, evaluation of their role as leads in antitumor drug research. Marine Drugs, 11(11), 4451-4463, 2013. 
[5] Esposito, G., Teta, R., Miceli, R., Ceccarelli, L., Della Sala, G., Camerlingo, R., Irollo, E., Mangoni, A., Pirozzi, G. \& Costantino, V., Isolation and assessment of the in vitro anti-tumor activity of smenothiazole $\mathrm{A}$ and $\mathrm{B}$, chlorinated thiazole-containing peptide/polyketides from the caribbean sponge, smenospongia aurea. Marine Drugs, 13, 444-459, 2015.

[6] Pettit, G.R., Kamano, Y., Herald, C L., Tuinman, A.A., Boettner, F.E., Kizu, H., Schmidt, J.M., Baczynskyj, L., Tomer, K.B. \& Bontems, R.J., The isolation and structure of a remarkable marine animal antineoplastic constituent: dolastatin 10, Journal of American Chemical Society, 109, 6883-6885,1987.

[7] Paerl, H.W. \& Huisman, J., Blooms like it hot. Science, 320, 57-58, 2008. http://dx.doi.org/10.1126/science. 1155398

[8] Davis, T.W. \& Gobler, C.J., Preface for Special Issue on Global expansion of harmful cyanobacterial blooms: diversity, ecology, causes, and controls, Harmful Algae, 54, 1-3, 2016. http://dx.doi.org/10.1016/j.hal.2016.02.003

[9] Kutser, T., Metsamaa, L., Strombeck, N. \& Vahtmae, E., Monitoring cyanobacterial blooms by satellite remote sensing, Limnol Oceanogr, 49, 2179-2189, 2004. http://dx.doi.org/10.4319/lo.2004.49.6.2179

[10] Lega, M., Kosmatka, J., Ferrara, C., Russo, F., Napoli, R.M.A. \& Persechino, G., Using advanced aerial platforms and infrared thermography to track environmental contamination. Environmental Forensics, 13(4), 332-338, 2012.

http://dx.doi.org/10.1080/15275922.2012.729002

[11] Errico, A., Angelino, C.V., Cicala, L., Persechino, G., Ferrara, C., Lega, M., Vallario, A., Parente, C., Masi, G., Gaetano, R., Scarpa, G., Amitrano, D., Ruello, G., Verdoliva, L. \& Poggi, G., Detection of environmental hazards through the feature-based fusion of optical and SAR data: a case study in southern Italy. International Journal of Remote Sensing, 36(13), 3345-3367, 2015. http://dx.doi.org/10.1080/01431161.2015.1054960

[12] Teta, R., Della Sala, G., Glukhov, E., Gerwick, L., Gerwick, W.H., Mangoni, A. \& Costantino, V., Combined LC-MS/MS and molecular networking approach reveals new cyanotoxins from the 2014 cyanobacterial bloom in Green Lake, seattle. Environmenal Science and Technology, 49(24), 14301-14310, 2015. http://dx.doi.org/10.1021/acs.est.5b04415

[13] Green Lake Water Quality: Water Quality Monitoring Results for Water Year 2013, Available at: http://green2.kingcounty.gov/smalllakes/Reports\%5CGreen_WY13.pdf

[14] Washington State Toxic Algae, available at: https://www.nwtoxicalgae.org

[15] Yang, K., Zhao, X., Xu, Q., Peng, S. \& Hong, L., Remote sensing recognition, concentration classification and dynamic analysis of cyanobacteria bloom in Dianchi Lake based on MODIS data. 20th International Conference on Geoinformatics, 1-5, 2012.

[16] Costantino, V., Fattorusso, E., Imperatore, C., Mangoni, A. \& Teta, R., Amphiceramide A and B, Novel Glycosphingolipids from the Marine Sponge Amphimedon compressa. European Journal of Organic Chemistry, 13, 2112-2119, 2009. http://dx.doi.org/10.1002/ejoc.200801230

[17] Watrous, J.; Roach, P., Alexandrov, T., Heath, B.S., Yang, J.Y., Kersten, R.D., van der Voort, M., Pogliano, K., Gross, H., Raaijmakers, J. M., Moore, B. S., Laskin, J., Bandeira, N. \& Dorrestein, P.C., Mass spectral molecular networking of living microbial colonies. Proceedings of the National Academy of Sciences of the United States of America, 109, E1743-E1752, 2012.

http://dx.doi.org/10.1073/pnas.1203689109 
[18] UCSD Computational Mass Spectrometer Website, available at: http://gnps.ucsd.edu/

[19] Della Sala, G., Hochmuth, T., Costantino, V., Teta, R., Gerwick, W., Gerwick, L., Piel, J. \& Mangoni, A., Polyketide genes in the marine sponge Plakortis simplex: A new group of mono-modular type I polyketide synthases from sponge symbionts. Environmental Microbiology Reports, 5(6), 809-818, 2013. http://dx.doi.org/10.1111/1758-2229.12081

[20] Della Sala, G., Hochmuth, T., Teta, R., Costantino, V. \& Mangoni, A., Polyketide synthases in the microbiome of the marine sponge Plakortis halichondrioides: a metagenomic update. Marine Drugs, 12(11), pp. 5425-5440, 2014. http://dx.doi.org/10.3390/md12115425

[21] Winnikoff, J.R., Glukhov, E., Watrous, J., Dorrestein, PC., Gerwick, WH., Quantitative Molecular networking to profile cyanobacterial metabolomes. The Journal of Antibiotics, 67, 105-112, 2014. http://dx.doi.org/10.1038/ja.2013.120

[22] Lega, M., Ferrara, C., Persechino, G. \& Bishop, P., Remote sensing in environmental police investigations: Aerial platforms and an innovative application of thermography to detect several illegal activities, Environmental Monitoring and Assessment, 186(12), 8291-8830, 2014. http://dx.doi.org/10.1007/s10661-014-4003-3

[23] Lega, M. \& Persechino, G., GIS and infrared aerial view: Advanced tools for the early detection of environmental violations, WIT Transactions on Ecology and the Environment, 180, 225-235, 2014.

[24] Lega, M. \& Persechino, G., GIS and infrared aerial view: Advanced tools for the early detection of environmental violations. WIT Transactions on Ecology and the Environment, 180, 225-235, 2014. http://dx.doi.org/10.2495/WM140191

[25] Persechino, G., Lega, M., Romano, G., Gargiulo, F. \& Cicala, L., IDES project: An advanced tool to investigate illegal dumping. WIT Transactions on Ecology and the Environment, 173, 603-614, 2013. http://dx.doi.org/10.2495/SDP130501

[26] Lega, M., D’Antonio, L. \& Napoli, R.M.A., Cultural heritage and waste heritage: advanced techniques to preserve cultural heritage, exploring just in time the ruins produced by disasters and natural calamities. WIT Transactions on Ecology and the Environment, 140, 123-134, 2010. http://dx.doi.org/10.2495/WM100121 